Article

\title{
Separation and Purification of Biogenic 1,3-Propanediol from Fermented Glycerol through Flocculation and Strong Acidic Ion-Exchange Resin
}

\author{
Laura Mitrea $^{1}$ D, Loredana Florina Leopold ${ }^{2}$, Cosmina Bouari ${ }^{3, *}$ and Dan Cristian Vodnar ${ }^{1,2, *(D)}$ \\ 1 Institute of Life Sciences, University of Agricultural Sciences and Veterinary Medicine Cluj-Napoca, \\ Calea Mănăștur 3-5, 400372 Cluj-Napoca, Romania; laura.mitrea@usamvcluj.ro \\ 2 Faculty of Food Science and Technology, University of Agricultural Sciences and Veterinary Medicine \\ Cluj-Napoca, Calea Mănăştur 3-5, 400372 Cluj-Napoca, Romania; loredana.leopold@usamvcluj.ro \\ 3 Faculty of Veterinary Medicine, University of Agricultural Sciences and Veterinary Medicine Cluj-Napoca, \\ Calea Mănăstur 3-5, 400372 Cluj-Napoca, Romania \\ * Correspondence: cosmina.bouari@usamvcluj.ro (C.B.); dan.vodnar@usamvcluj.ro (D.C.V.); \\ Tel.: +40-7427-36-657 (C.B.); +40-7473-41-881 (D.C.V.)
}

Received: 5 October 2020; Accepted: 25 November 2020; Published: 26 November 2020

\begin{abstract}
In the present work, was investigated the separation and purification procedure of the biogenic 1,3-propanediol (1,3-PD), which is a well-known valuable compound in terms of bio-based plastic materials development. The biogenic 1,3-PD was obtained as a major metabolite through the glycerol fermentation by Klebsiella pneumoniae DSMZ 2026 and was subjected to separation and purification processes. A strong acidic ion exchange resin in $\mathrm{H}^{+}$form was used for 1,3-PD purification from the aqueous solution previously obtained by broth flocculation. The eluent volume was investigated considering the removal of the secondary metabolites such as organic acids (acetic, citric, lactic, and succinic acids) and 2,3-butanediol (2,3-BD), and unconsumed glycerol. It was observed that a volume of $84 \mathrm{~mL}$ of ethanol $75 \%$ loaded with a flow rate of $7 \mathrm{~mL} / \mathrm{min}$ completely remove the secondary metabolites from $10 \mathrm{~mL}$ of concentrated fermented broth, and pure biogenic $1,3-\mathrm{PD}$ was recovered in $128 \mathrm{~mL}$ of the eluent.
\end{abstract}

Keywords: 1,3-propanediol; cationic resin; flocculation; Klebsiella pneumoniae; purification

\section{Introduction}

Residual biomass, such as raw glycerol derived from biodiesel manufacturing, represents a sustainable source of nutrients for the biological catalysts that can convert it into valuable metabolites [1-4], which can further represent base materials for the production of eco-friendly plastic materials, for example, polytrimethylene-terephthalate (PTT) $[5,6]$.

Even though 1,3-PD biosynthesis from renewable biomass is very attractive from the environmental and economic point-of-view, unlike its production through chemical synthesis, the high purity of biogenic 1,3-PD needed for further industrial usages constitutes a bottleneck of the entire process $[7,8]$. Mainly because the biogenic 1,3-PD is generated in low amounts in the cultivation media, the removal of other constituents like cells, proteins, salts, organic acids, and alcohols increases the total cost of the purification process for the targeted compound $[9,10]$.

The separation of 1,3-PD from the cultivation media usually implies at least two steps. Commonly, the coarse fragments like cells and cell debris are removed by centrifugation, filtration, or microfiltration from the fermented broth [11]. The protein fractions, macromolecular pigments, and inorganic salts can 
be successfully separated from the cultivation media by nontoxic methods such as flocculation with a mixture of chitosan or polyacrylamide [12-14], activated charcoal [15,16], and kieselguhr (diatomite earth) $[8,17,18]$.

Many purification methods have been investigated in the last two decades $[8,9,11,19-23]$ for an increased yield of 1,3-PD, and ion exchange resins are considered as sustainable materials for 1,3-PD recovery due to their ability to be regenerated periodically [24-26]. In the case of 1,3-PD, divinylbenzene-based cation-exchange resins in different forms $\left(\mathrm{H}^{+}, \mathrm{Ca}^{2+}, \mathrm{Ag}^{+}, \mathrm{Na}^{+}, \mathrm{Pb}^{2+}, \mathrm{Zn}^{2+}, \mathrm{Li}^{+}\right.$, $\mathrm{Co}^{2+}, \mathrm{Cu}^{2+}$ ) are suitable for the increased recovery of the compound. Still, resins in $\mathrm{H}^{+}$and $\mathrm{Ca}^{2+}$ have been proven to have higher efficiency in 1,3-PD purification towards other forms of resins $[8,20,27]$.

Besides ion-exchange resins, other methods of 1,3-PD purification have been reported, but many of them have certain drawbacks especially due to their high cost of the downstream process, or because of their increased grade of toxicity [9]. Wu et al. [28] used electrodialysis through bipolar membranes to desalinate the fermentation broth, to recover the salts, and to convert them into high-added-value by-products [28]. In this case, the membrane reuse limits its working life and increases the cost of the purification process. Hao et al. applied a reactive extraction of 1,3-PD from a dilute aqueous solution by using aldehydes (propionaldehyde, butyraldehyde, and isobutyraldehyde). Aldehydes that were found in excess replaced 1,3-dioxanes, from where 1,3-PD were further extracted by using reactive distillation equipment [7]. The reactive extraction of 1,3-PD utilizing acetaldehyde instead was applied by Malinowski [29], who obtained 2-methyl-1,3-dioxane which was further subjected to extraction by using organic solvents such as $o$-xylene, toluene, or ethylbenzene that were converted back to 1,3-PD by hydrolyzation [29]. In reactive extraction scenarios, the purification processes have some disadvantages because the aldehydes used as both extractant and reactant have a certain degree of toxicity, and at the same time, they can react with other alcohols from the fermentation broth like ethanol, 2,3-BD, or glycerol [30]. In a study conducted by Waszak et al., nanofiltration was applied as a cheaper method to separate 1,3-PD from fermented glycerol by Citrobacter freundii [31]. In their investigation, the fermented broth consisting of up to $5 \mathrm{~g} / \mathrm{L} 1,3-\mathrm{PD}$ was subjected to nanofiltration to extract the interest compound. The authors used an active membrane of $150 \mathrm{~cm}^{2}$, model NF270 from Dow FilmTec (Minneapolis, MN, USA). The membrane retained the major part of the cultivation media components like salts $\left(\mathrm{NH}_{4}{ }^{+}, \mathrm{SO}_{4}{ }^{-}, \mathrm{K}^{+}, \mathrm{Na}^{+}, \mathrm{PO}_{4}{ }^{3-}\right.$ ), carboxylic acids (lactic, succinic, acetic acids), or glycerol, and separated 1,3-PD. In addition, there was also the possibility to reuse the membrane for a second filtration to diminish the total cost of the operation [31].

A particular aspect that makes the 1,3-PD separation process more complicated is related to its high hydrophilic characteristics, and its close boiling point to 2,3-BD and glycerol. In this context, the recovery of 1,3-PD from a microbial fermentation media would consume a large amount of energy and would make up over $50 \%$ of the total production costs $[9,22]$. In addition, the elevated polarity of 1,3-PD makes its extraction difficult from the aqueous system. Müller and Górak [32] investigated the possibility of 1,3-PD separation by applying two-phase aqueous systems. The authors of this study tested various ionic liquids starting with 1-butyl-3-methylimidazolium trifluoromethansulfonate as the initial ionic liquid, and different anions and cations like dicyanamide, thiocyanate, methysulfate (as anions), and 1-butyl-3-methylmorpholinium, 1-butyl-3-methylpyrrolidinium, 1-ethyl-3-methylimidazolium, and 1-methoxyethyl-3-methylimidazolium (as cations). The results of this study highlight that all of the investigated two-phase systems were appropriate for the extraction of 1,3-PD. Moreover, the 1,3-PD distribution coefficient is closely correlated with the polarity or hydrogen-bond accepting strength of the cation and anion [32].

In the present work, the capacity of acidic ion-exchange resin in $\mathrm{H}^{+}$form (Amberlite IR-120H) to purify the biogenic 1,3-PD from the fermentation broth, after it was subjected to flocculation with chitosan, charcoal, and kieselguhr, was investigated. 


\section{Materials and Methods}

\subsection{Reagents}

All reagents used for the present work were analytically graded. 1,3-PD $\left(\mathrm{C}_{3} \mathrm{H}_{8} \mathrm{O}_{2}\right.$, purity $99 \%$, d: $1.053 \mathrm{~g} / \mathrm{cm}^{3}$, MW: $76.10 \mathrm{~g} / \mathrm{mol}$ ) was purchased from Alfa Aesar (Thermo Fisher Scientific GmbH, Kandel, Germany); 2,3-BD $\left(\mathrm{C}_{4} \mathrm{H}_{10} \mathrm{O}_{2}\right.$, purity $98 \%$, d: $1.002 \mathrm{~g} / \mathrm{cm}^{3}$, MW: $\left.90.12 \mathrm{~g} / \mathrm{mol}\right)$ was provided by Sigma-Aldrich (Sigma-Aldrich Trading Co., Shanghai, China); glycerol $\left(\mathrm{C}_{3} \mathrm{H}_{8} \mathrm{O}_{3}\right.$, purity $99 \%$, d: $1.256 \mathrm{~g} / \mathrm{cm}^{3}$, MW: $92.10 \mathrm{~g} / \mathrm{mol}$ ); organic acids (citric, succinic, lactic, and acetic acids), ethanol, and the components used for cultivation media were supplied by VWR Chemicals (VWR International $\mathrm{GmbH}$, Langenfeld, Germany).

Calcinated kieselguhr (Celite Filter Cel) was acquired from Honeywell-Fluka (Honeywell Specialty Chemicals GmbH, Seelze, Germany). Chitosan (Poly-D-glucosamine) and cationic resin (Amberlite IR 120, hydrogen bond) were bought from Sigma-Aldrich (Sigma-Aldrich Trading Co., Shanghai, China).

The instrumentation used for the experimental part of the present work consisted of a bioreactor (Eppendorf, Hamburg, Germany), a centrifuge (Eppendorf, Hamburg, Germany), a magnetic stirrer plate (Ika Labortechnik, Staufen, Germany), a glass vacuum filtration unit (VWR International $\mathrm{GmbH}$, Langenfeld, Germany), a rotary evaporator with vacuum (Heidolph Instruments, Schwabach, Germany), and an High Performance Liquid Chromatography with Refractive Index Detector system (HPLC-RID, Agilent 1200, Santa Clara, CA, USA).

\subsection{Fermentation Process}

The bacterial strain used for the fermentation of glycerol was K. pneumoniae DSMZ 2026, and it was purchased from the German Collection of Microorganisms and Cell Cultures (DSMZ, Braunschweig, Germany). The strain was cultivated in a 5-L Eppendorf bioreactor (model: BioFlo 320, one unit) filled with 2 L of culture broth (Eppendorf, Hamburg, Germany). The cultivation medium components and the fermentation conditions were described in our previous publications [33,34]. The fermented broth consisting of fully developed bacterial cells and metabolites was collected and subjected to separation and purification processes.

\subsection{Broth Flocculation}

The cell biomass from the fermentation broth was removed by high-speed centrifugation (10,000 RPM) for $10 \mathrm{~min}$ at $4{ }^{\circ} \mathrm{C}$ (centrifuge 5810R, Eppendorf, Hamburg, Germany). The supernatant was collected and stored at $-20^{\circ} \mathrm{C}$ for later use.

To remove the organic macromolecules, cells debris, and proteins, the fermentation broth was flocculated with chitosan $0.06 \%$, calcinated kieselguhr $6 \%$, and activated charcoal $2 \%$, afterwards the fermentation broth $\mathrm{pH}$ was adjusted to 5 with $\mathrm{HCl} 2 \mathrm{M}$, after the method proposed by Wang et al. (2015) [8]. The mixture was stirred at $250 \mathrm{rpm}$ for $30 \mathrm{~min}$ at room temperature $\left(23^{\circ} \mathrm{C}\right)$ on a magnetic plate, then vacuum-filtered through MN615 filters, until a clear solution was obtained. The vacuum filtration yield was established using the formula Equation (1).

Filtration yield $(\%)=$ volume of clear fermented broth $(\mathrm{mL}) /$ volume of fermented broth without biomass $(\mathrm{mL}) \times 100$

The clear, fermented broth was concentrated through vacuum distillation for about an hour at $95{ }^{\circ} \mathrm{C}$ to remove the water and the ethanol content. The metabolites' quantity in nonflocculated, flocculated, and concentrated solutions was established by HPLC.

\subsection{Purification through an Ion Exchange Resin}

The filtered solution containing 1,3-PD, 2,3-BD, fractions of glycerol, and organic acids (citric, succinic, lactic, and acetic acids) was passed through an acidic cation exchange resin (Amberlite IR120 $\mathrm{H})$. We filled a glass column of $50-\mathrm{cm}$ height and $3-\mathrm{cm}$ diameter with cationic resin up to $30 \mathrm{~cm}$, to 
observe the purification yield by using ethanol $75 \%$ as eluent. The eluent volume needed to pass through the packed column was calculated using the formula Equation (2).

$$
\text { Veluent }=\pi r^{2} h
$$

where $r$-column radius (or diameter/2) $(\mathrm{cm}), h$ —column height $(\mathrm{cm})$

\section{Purification Process Using a 30-cm Resin Bed}

A $50-\mathrm{cm}$ glass column with a diameter of $3 \mathrm{~cm}$ was packed with $30 \mathrm{~cm}$ of cationic resin. Before the sample passage through the column, the resin beds were pretreated with $2 \mathrm{M} \mathrm{HCl}, 2 \mathrm{M} \mathrm{NaOH}$, and $2 \mathrm{M} \mathrm{HCl}$, and then rinsed with deionized water, as mentioned by Wang et al. [8]. Then, $10 \mathrm{~mL}$ of filtered broth was passed through the column and eluted with ethanol $75 \%$ at a flow rate of $7 \mathrm{~mL} / \mathrm{min}$. At regular intervals, $6 \mathrm{~mL}$ of effluent was collected to determine the concentration of organic acids, 1,3-PD, 2,3-BD, and glycerol.

Figure 1 illustrates the main steps for obtaining pure 1,3-PD from glycerol fermentation.

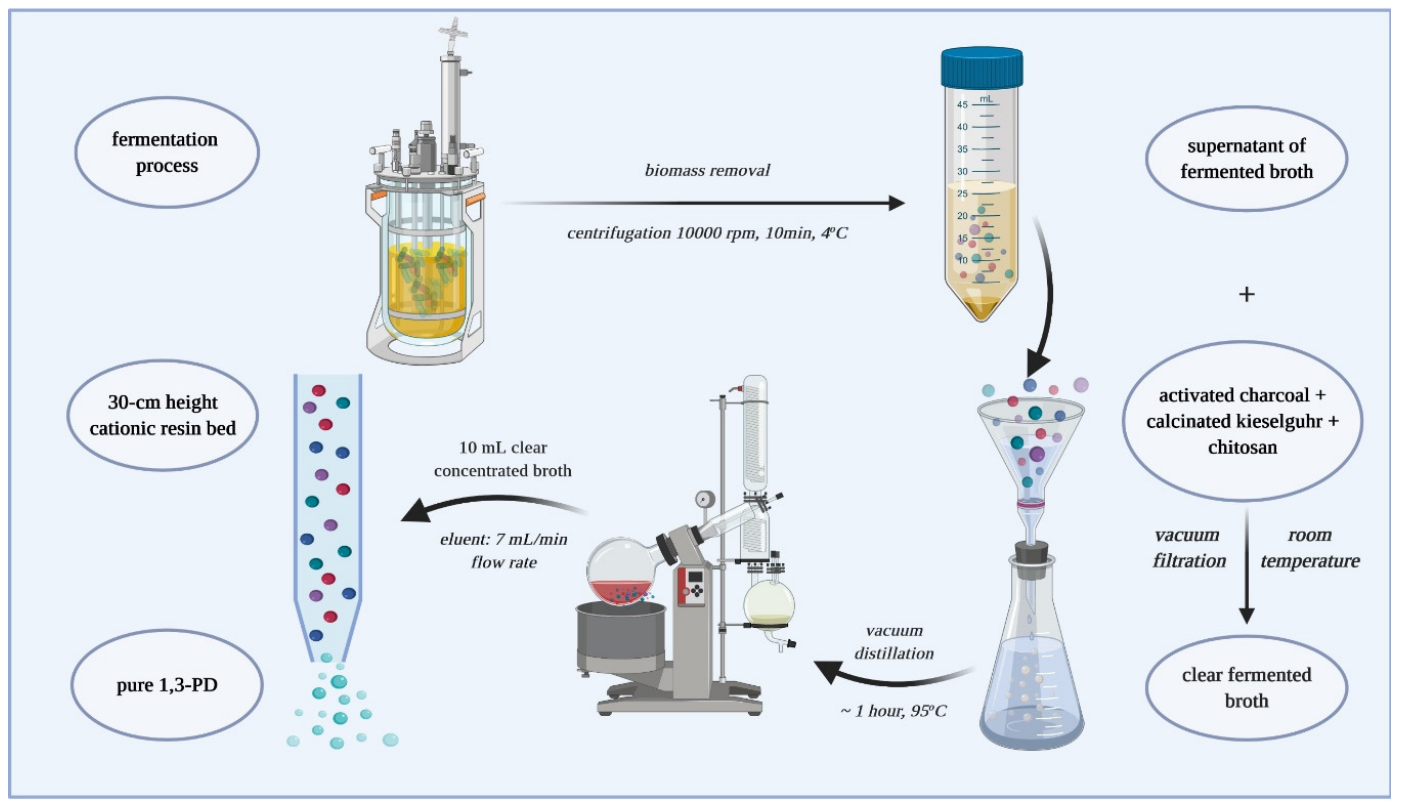

Figure 1. Main steps for obtaining pure 1,3-PD (broth fermentation, biomass separation, flocculation, concentration, purification).

\subsection{HPLC Analysis}

The polyols (1,3-PD, 2,3-BD, and glycerol), the organic acids (citric, succinic, lactic, and acetic acids), and ethanol were identified through HPLC. The system was equipped with a quaternary pump, solvents degasser, and manual injector coupled with a refractive index detector (RID) (Agilent 1200, Santa Clara, CA, USA).

The separation of the compounds was performed on a Polaris Hi-Plex H column, $300 \times 7.7 \mathrm{~mm}$ (Agilent Technologies, CA, USA), using the $5 \mathrm{mM} \mathrm{H}_{2} \mathrm{SO}_{4}$ mobile phase with a flow rate of $0.6 \mathrm{~mL} / \mathrm{min}$, column temperature $T=80^{\circ} \mathrm{C}$, and RID temperature $T=35^{\circ} \mathrm{C}$. The elution of the compounds was run for $25 \mathrm{~min}$.

The data acquisition and the interpretation of the results were made by using OpenLab CDS-ChemStation Edition software (Agilent Technologies, CA, USA). 


\section{Results and Discussions}

The separation and purification of 1,3-PD with high yields is still a challenging process from the technological, environmental, and economic point of view. The industrial production of 1,3-PD utilizing microbes might be negatively influenced, so the purification process of the targeted compound from the microbial fermented media must be optimized and made much more feasible and accessible. In our study, we applied an environment-friendly protocol to separate and purify the interest metabolite from the cultivation broth, namely flocculation, and purification through ion exchange resin.

\subsection{Broth Flocculation and Concentration}

Bacterial cells of K. pneumoniae DSMZ 2026 were removed from the culture broth by high-speed centrifugation after $24 \mathrm{~h}$ of batch fermentation for 1,3-PD production (Figure 2). The centrifuged culture broth was subjected further to flocculation. The nontoxic flocculation process consisted of chitosan, calcinated kieselguhr, and activated charcoal addition to the cultivation broth, which removed all the colored impurities (proteins, salts, cellular debris) by giving a perfectly transparent solution of biogenic 1,3-PD from a cloudy yellow broth. The vacuum filtration yield was $85 \%$. The vacuum-filtered broth was further concentrated through vacuum distillation and about $265 \mathrm{~g} / \mathrm{L}$ of a slightly viscous $1,3-\mathrm{PD}$ being obtained as the main metabolite. Hao et al. [14] used flocculation with a mixture of cationic polyelectrolyte chitosan and nonionic polyelectrolyte polyacrylamide for 1,3-PD separation before its purification through reactive extraction with butyraldehyde. Firstly, the authors tested the flocculation with chitosan and polyacrylamide individually, but the broth did not clarify well, especially in the case of broth flocculated with polyacrylamide where it turned more turbid than the original. The authors achieved a recovery ratio of the supernatant liquor to the broth of $99 \%$, the concentration of the metabolites not being mentioned at this step [14].

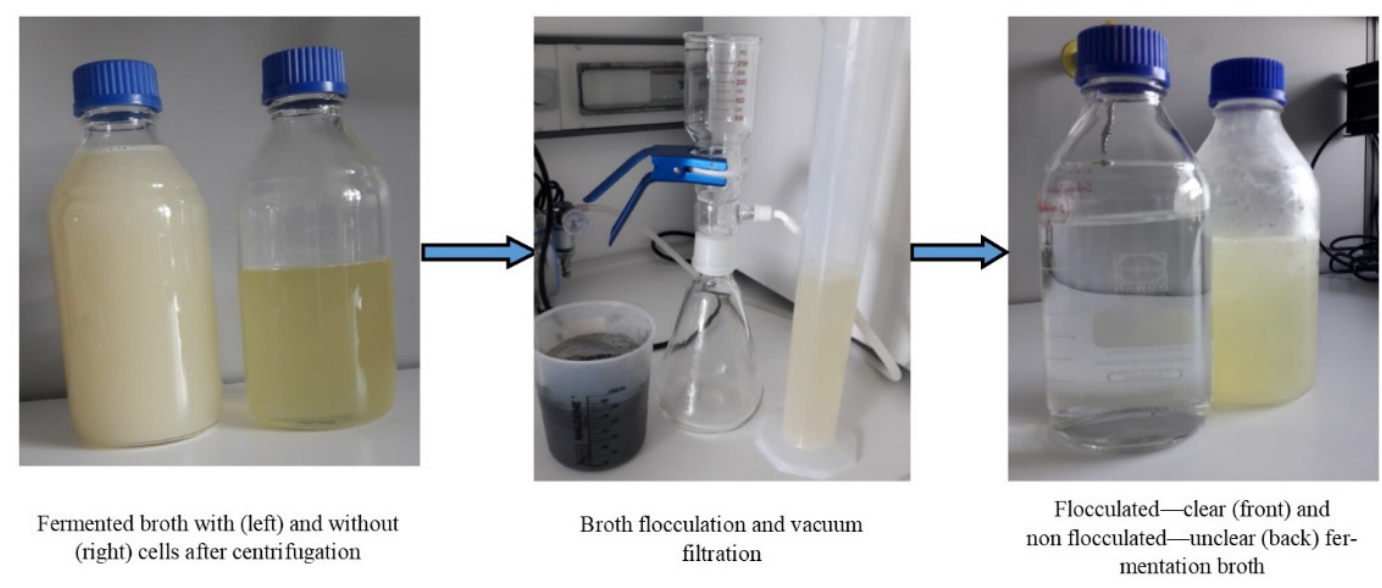

Figure 2. Bacterial cell removal and broth flocculation.

The cultivation broth was analyzed by HPLC (Figure 3) before flocculation, after flocculation, and after vacuum concentration, and the results are presented in Table 1 . In the clear broth, the metabolite concentration slightly decreased towards the cultivation media before flocculation. After almost an hour of vacuum distillation, the quantity of the metabolite was significantly increased. 


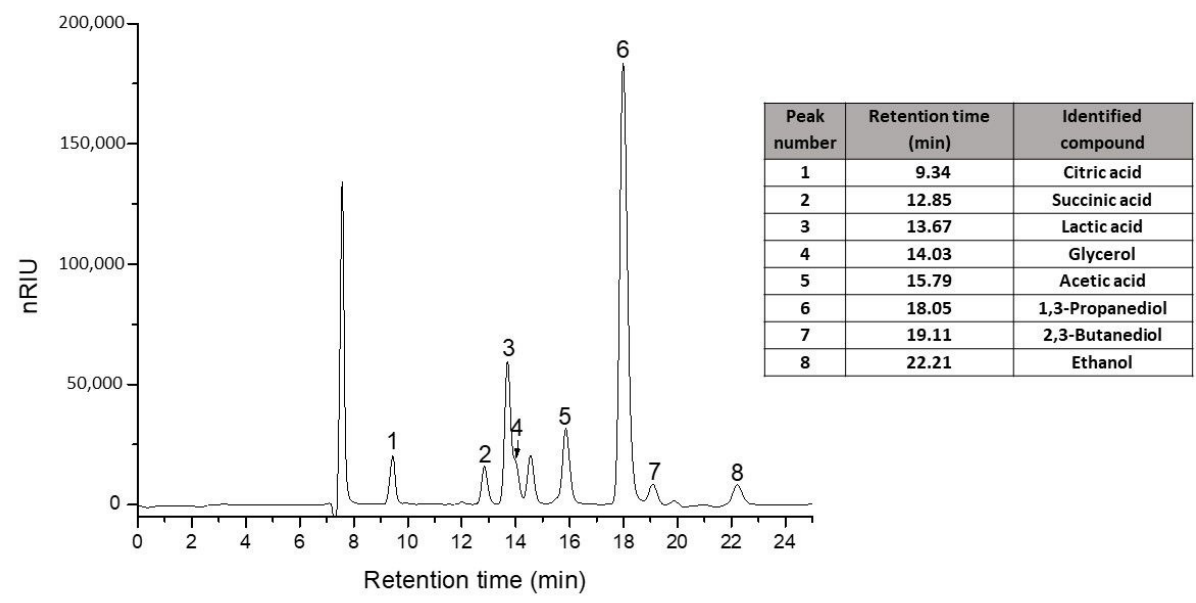

Figure 3. Standard chromatogram and retention time ( $\mathrm{min}$ ) for the interest compounds on a Polaris Hi-Plex H column, Refractive Index (RI) detector.

Table 1. Metabolites and unconsumed glycerol concentration $(\mathrm{g} / \mathrm{L})$ in the fermentation broth (before/after flocculation and after concentration).

\begin{tabular}{ccccccccc}
\hline $\begin{array}{c}\text { Medium/Compounds } \\
\text { Header }\end{array}$ & $\begin{array}{c}\text { Citric } \\
\text { Ac. }\end{array}$ & $\begin{array}{c}\text { Succinic } \\
\text { Ac. }\end{array}$ & $\begin{array}{c}\text { Lactic } \\
\text { Ac. }\end{array}$ & Glycerol & $\begin{array}{c}\text { Acetic } \\
\text { Ac. }\end{array}$ & 1,3-PD & 2,3-BD & Ethanol \\
\hline Nonflocculated Fermentation Broth & 1.62 & 1.17 & 3.42 & 0.30 & 4.06 & 28.86 & 4.89 & 1.43 \\
\hline Flocculated (Clear) Fermentation Broth & 1.31 & 0.97 & 2.83 & 0.28 & 3.28 & 26.88 & 2.93 & 1.23 \\
\hline Concentrated Fermentation Broth & 12.52 & 9.22 & 30.01 & 3.52 & 27.56 & 265.06 & 33.31 & - \\
\hline
\end{tabular}

Compared with other studies, the starting concentration of the metabolites in our study is lower (Table 1). For example, Hao et al. [14] reported 53.5 g/L 1,3-PD, 7.5 g/L 2,3-BD, 27.6 g/L glycerol, 8.1 g/L ethanol, $5.9 \mathrm{~g} / \mathrm{L}$ lactate, $10.5 \mathrm{~g} / \mathrm{L}$ acetate, and $5.6 \mathrm{~g} / \mathrm{L}$ succinate in the fermented broth before being subjected to flocculation [14].

\subsection{Purification of Biogenic 1,3-PD through a Cationic Exchange Resin}

The resin selection was conducted based on a literature review $[8,20]$. The concentrated, clear broth obtained after biomass removal, flocculation, and vacuum distillation, was separated using the chromatographic purification method [8].

After being treated with acid-base-acid solutions, the $30-\mathrm{cm}$ resin bed was loaded with $10 \mathrm{~mL}$ of concentrated clear broth and eluted with a volume of $212 \mathrm{~mL}$ ethanol $75 \%$, at a flow rate of $7 \mathrm{~mL} / \mathrm{min}$. After each volume of eluent loaded in the packed column, about $6 \mathrm{~mL}$ of downloaded samples were withdrawn to establish the eluent volume needed to remove the entire amount of secondary metabolites (organic acids and 2,3-BD) and the unconsumed glycerol during fermentation; $0.05 \mathrm{~mL}$ was used for HPLC analysis.

We observed that a volume of $84 \mathrm{~mL}$ ethanol $75 \%$ loaded on the resin column which corresponds to 12 min of elution, completely separated the organic acids, glycerol, and 2,3-BD (Figure 4). An explanation of the clear cut of the components after $12 \mathrm{~min}$ of elution may be due to the specific affinity to the stationary/mobile phases. The organic acids, 2,3-BD, and glycerol were flushed earlier mainly because of their elevated affinity to the mobile phase. In the case of 1,3-PD, this has a higher affinity to the stationary phase represented by the column of the resin beds. 1,3-PD creates steric bonds with the cationic resin, an aspect that cumbers the elution process with an increased volume of eluent and longer time to pass through the column being necessary. So, after the column resin loading with the rest of the eluent volume (128 mL) (Figure 4), $80.708 \mathrm{~g} / \mathrm{L}$ of pure biogenic 1,3-PD, in 18 min of elution was collected. The collected samples consisting of pure 1,3-PD (about $100 \mathrm{~mL}$ ) were gathered in a glass balloon and concentrated by vacuum distillation at $95^{\circ} \mathrm{C}$ until water and ethanol were completely 
removed. About $15 \mathrm{~mL}$ of viscous solution was obtained, with the final content of pure 1,3-PD being $612.03 \mathrm{~g} / \mathrm{L}$.

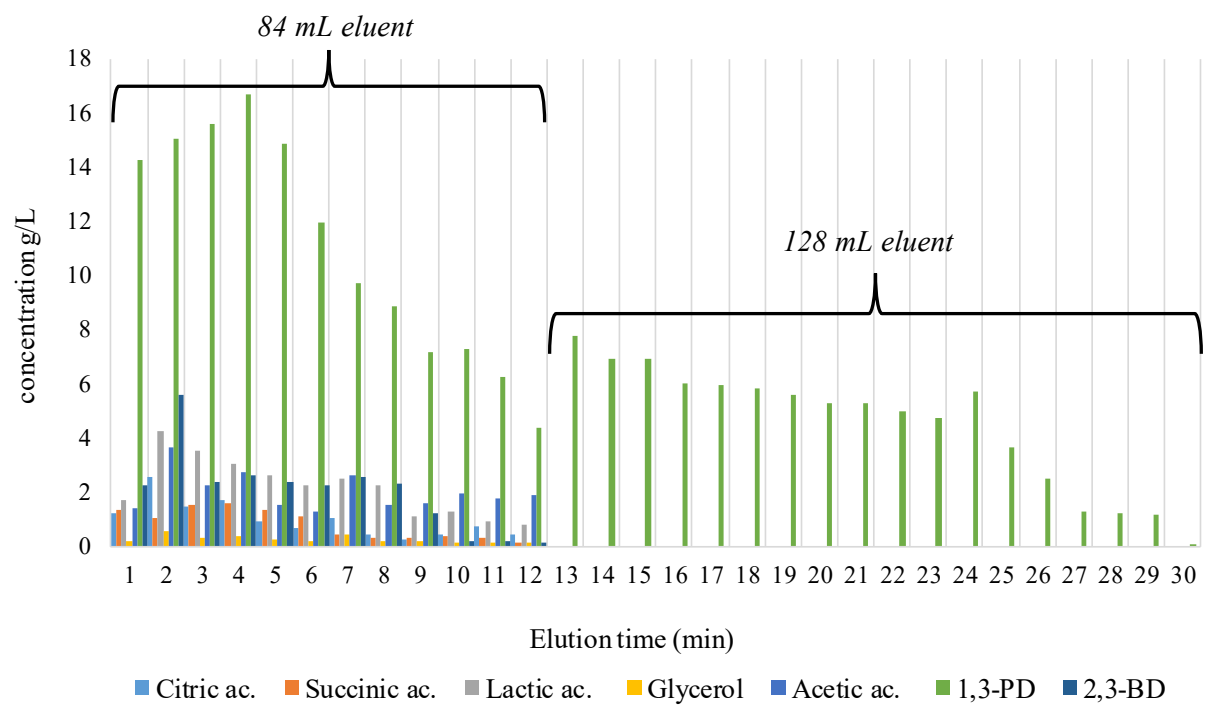

Figure 4. Results obtained for the cationic resin separation of $10 \mathrm{~mL}$ of concentrated fermented broth.

In a study conducted by Leurruk et al [25], between 80 and $160 \mathrm{~g} / \mathrm{L}$ of pure 1,3-PD was recovered from an aqueous solution of a synthetic mixture by using two cationic exchange resins, Amberlite type XAD-7 and XAD-16. Hao et al. [14] reported that a mixture of metabolites was obtained in a reactive distillation column using the strong acidic cation-exchange resin as a catalyst, specifically 407 g/L 1,3-PD, 252 g/L 2,3-BD, 277 g/L glycerol, and 146 g/L glycerol acetals were obtained [14].

Compared with other techniques used for 1,3-PD separation and purification mentioned in the literature, the method presented in this paper presents some advantages. First, the removal of coarse fragments from the cultivation media implies only centrifugation. Second, the removal of proteins, cellular debris, and other color impurities can be successfully performed by nontoxic flocculation with chitosan, charcoal, and kieselguhr. Third, the removal of organic acids and unconsumed glycerol from the broth can be done by eluting with ethanol a strong acidic resin, like Amberlite IR-120H which can be regenerated periodically. However, there is also a shortcoming of our proposed method considering that an important quantity of 1,3-PD is discharged in the first stage of the purification during the first 12 min of elution. To recover 1,3-PD from this stage, another separation-purification method would be appropriate, like preparative HPLC or another type of resin column.

Regardless, since 1,3-PD has large applicability in the manufacture of biodegradable products such as fibers [35], plastic materials [36], textiles [37], cosmetics [38], food additives [39], or coating materials [40,41], the biogenic 1,3-PD purified through 'green' methods and materials represents a feasible alternative to the synthetic 1,3-PD, from an economic and environmental point of view.

\section{Conclusions}

Biogenic 1,3-PD was obtained through glycerol fermentation using K. pneumoniae DSMZ 2026 as a bioconverter. The cultivation media consisted of 1,3-PD, 2,3-BD, organic acids (lactic, citric, succinic, and acetic acids), and ethanol. The main steps to obtain pure biogenic 1,3-PD from the cultivation broth were separation through flocculation with a mixture of chitosan, activated charcoal, and kieselguhr, and purification through a cation exchange resin $\mathrm{H}^{+}$form. It was observed that cell debris, pigments, and protein fragments were completely removed through flocculation resulting in a perfectly transparent, aqueous solution of metabolites, with low differences between their concentrations before and after the process. The concentrated broth-10 mL-was loaded in a $30-\mathrm{cm}$ height resin column, and a volume of $84 \mathrm{~mL}$ of ethanol $75 \%$ as eluent loaded with a flow rate of 
$7 \mathrm{~mL} / \mathrm{min}$ was necessary to entirely remove the secondary metabolites (organic acids and 2,3-BD) and the residual glycerol, during $12 \mathrm{~min}$ of eluation. Pure biogenic 1,3-PD was recovered in $128 \mathrm{~mL}$ of the eluent, which, after being subjected to vacuum concentration (7 times concentrated), yielded $91 \%$ of biogenic 1,3-PD in its pure form.

In the light of the scope of our research, the results presented in this paper make the separation and purification method valuable considering the environmental and economic aspects, as the materials used are biodegradable and renewable. The biogenic 1,3-PD obtained through the microbial conversion of glycerol and purified through reusable ionic resin represents a feasible alternative to the synthetic production of 1,3-PD, and at the same time a valuable alternative that would answer to the increased demands of 1,3-PD on the market.

Author Contributions: Conceptualization, L.M. and D.C.V.; Methodology, L.M. and D.C.V.; Investigation, L.M. and L.F.L.; Writing—original draft preparation, L.M.; Writing—review and editing, C.B. and D.C.V. All authors have read and agreed to the published version of the manuscript.

Funding: This research was funded by the Ministry of Research and Innovation, CNCS-UEFISCDI, project PN-III-P1-1.1-PD-2019-0679 (SuccinYst), and under the frame of European Social Found, Human Capital Operational Programme 2014-2020, project no. POCU/380/6/13/125171.

Conflicts of Interest: The authors declare no conflict of interest.

\section{References}

1. Mitrea, L.; Trif, M.; Cătoi, A.-F.; Vodnar, D.C. Utilization of biodiesel derived-glycerol for 1,3-PD and citric acid production. Microb. Cell Factor. 2017, 16, 190. [CrossRef] [PubMed]

2. Laura, M.; Călinoiu, L.-F.; Precup, G.; Bindea, M.; Rusu, B.; Trif, M.; Ferenczi, L.J.; Ştefănescu, B.E.; Vodnar, D.C. Inhibitory potential of lactobacillus plantarum on Escherichia Coli. Bull. Univ. Agric. Sci. Veter-Med. Cluj-Napoca. Food Sci. Technol. 2017, 74, 99. [CrossRef]

3. Laura, M.; Ranga, F.; Fetea, F.; Dulf, F.; Rusu, A.; Trif, M.; Vodnar, D.C. Biodiesel-derived glycerol obtained from renewable biomass-A suitable substrate for the growth of Candida zeylanoides yeast strain ATCC 20367. Microorganisms 2019, 7, 265. [CrossRef]

4. Teleky, B.-E.; Martău, G.-A.; Ranga, F.; Chețan, F.; Vodnar, D.C. Exploitation of lactic acid bacteria and baker's yeast as single or multiple starter cultures of wheat flour dough enriched with soy flour. Biomolecules 2020, 10, 778. [CrossRef] [PubMed]

5. Vodnar, D.C.; Dulf, F.; Pop, O.L.; Socaciu, C. L (+)-lactic acid production by pellet-form Rhizopus oryzae NRRL 395 on biodiesel crude glycerol. Microb. Cell Factor. 2013, 12, 92. [CrossRef] [PubMed]

6. Teleky, B.-E.; Vodnar, D.-C. Biomass-derived production of itaconic acid as a building block in specialty polymers. Polymers 2019, 11, 1035. [CrossRef]

7. Hao, J.; Liu, H.; Liu, D. Novel route of reactive extraction to recover 1,3-propanediol from a dilute aqueous solution. Ind. Eng. Chem. Res. 2005, 44, 4380-4385. [CrossRef]

8. Wang, S.; Qiu, L.; Dai, H.; Zeng, X.; Fang, B. Highly pure 1,3-propanediol: Separation and purification from crude glycerol-based fermentation. Eng. Life Sci. 2015, 15, 788-796. [CrossRef]

9. Xiu, Z.-L.; Zeng, A.-P. Present state and perspective of downstream processing of biologically produced 1,3-propanediol and 2,3-butanediol. Appl. Microbiol. Biotechnol. 2008, 78, 917-926. [CrossRef]

10. Kumar, V.; Durgapal, M.; Sankaranarayanan, M.; Somasundar, A.; Rathnasingh, C.; Song, H.; Seung, D.; Park, S. Effects of mutation of 2,3-butanediol formation pathway on glycerol metabolism and 1,3-propanediol production by Klebsiella pneumoniae J2B. Bioresour. Technol. 2016, 214, 432-440. [CrossRef]

11. Anand, P.; Saxena, R.K.; Marwah, R.G. A novel downstream process for 1,3-propanediol from glycerol-based fermentation. Appl. Microbiol. Biotechnol. 2011, 90, 1267-1276. [CrossRef] [PubMed]

12. Cheng, J.; Xie, S.; Wang, S.; Xue, Y.; Jiang, L.; Liu, L. Optimization of protein removal from soybean whey wastewater using chitosan ultrafiltration. J. Food Process. Eng. 2016, 40. [CrossRef]

13. Agerkvist, I.; Eriksson, L.; Enfors, S.-O. Selective flocculation with Chitosan in Escherichia coli disintegrates: Effects of $\mathrm{pH}$ and nuclease treatment. Enzym. Microb. Technol. 1990, 12, 584-590. [CrossRef]

14. Hao, J.; Xu, F.; Liu, H.; Liu, D. Downstream processing of 1,3-propanediol fermentation broth. J. Chem. Technol. Biotechnol. 2005, 81, 102-108. [CrossRef] 
15. Krahnstöver, T.; Wintgens, T. Optimizing the flocculation of powdered activated carbon in wastewater treatment by dosing iron salt in single- and two-stage processes. J. Water Process. Eng. 2017, 20, 130-137. [CrossRef]

16. Baraniak, B.M.; Waleriańczyk, E. Flocculation. In Encyclopedia of Food Sciences and Nutrition, 2nd ed.; Caballero, B., Ed.; Academic Press: Oxford, UK, 2003; pp. 2531-2535. Available online: https://doi.org/10. 1016/B0-12-227055-X/00485-5 (accessed on 10 August 2020).

17. Gao, Q.; Duan, Q.; Wang, D.; Zhang, Y.; Zheng, C. Separation and purification of $\gamma$-aminobutyric acid from fermentation broth by flocculation and chromatographic methodologies. J. Agric. Food Chem. 2013, 61, 1914-1919. [CrossRef]

18. O'Mahony, K.; Freitag, R.; Dhote, B.; Hilbrig, F.; Müller, P.; Schumacher, I. Capture of bacteria from fermentation broth by body feed filtration: A solved problem? Biotechnol. Prog. 2006, 22, 471-483. [CrossRef]

19. Wang, Z.; Wu, Z.; Tan, T. Studies on purification of 1,3-propanediol by molecular distillation. Biotechnol. Bioprocess. Eng. 2013, 18, 697-702. [CrossRef]

20. Rukowicz, B.; Alejski, K. A biologically-derived 1,3-propanediol recovery from fermentation broth using preparative liquid chromatography. Sep. Purif. Technol. 2018, 205, 196-202. [CrossRef]

21. Boonsongsawat, T.; Shotipruk, A.; Tantayakom, V.; Prasitchoke, P.; Chandavasu, C.; Boonnoun, P.; Muangnapoh, C. Solvent extraction of biologically derived 1,3-propanediol with ethyl acetate and ethanol cosolvent. Sep. Sci. Technol. 2010, 45, 541-547. [CrossRef]

22. Cui, C.; Zhang, Z.; Chen, B. Environmentally-friendly strategy for separation of 1,3-propanediol using biocatalytic conversion. Bioresour. Technol. 2017, 245, 477-482. [CrossRef] [PubMed]

23. Hilaly, A.K.; Binder, T.P. Method of Recovering 1,3-Propanediol from Fermentation Broth. U.S. Patent No. US6479716B2, 11 December 2002.

24. Zhang, J.; Amini, A.; O’Neal, J.A.; Boyer, T.H.; Zhang, Q. Development and validation of a novel modeling framework integrating ion exchange and resin regeneration for water treatment. Water Res. 2015, 84, 255-265. [CrossRef] [PubMed]

25. Luerruk, W.; Shotipruk, A.; Tantayakom, V.; Prasitchoke, P.; Muangnapoh, C. Adsorption of 1,3-propanediol from synthetic mixture using polymeric resin as adsorbents. Front. Chem. Eng. China 2009, 3, 52-57. [CrossRef]

26. Cho, M.-H.; Joen, S.I.; Pyo, S.-H.; Mun, S.; Kim, J.-H. A novel separation and purification process for 1,3-propanediol. Process. Biochem. 2006, 41, 739-744. [CrossRef]

27. Rukowicz, B.; Miesiac, I.; Alejski, K. Separation of 1,3-propanediol from aqueous solutions by ion exchange chromatography. Pol. J. Chem. Technol. 2014, 16, 82-86. [CrossRef]

28. Wu, R.C.; Xu, Y.Z.; Song, Y.Q.; Luo, J.A.; Liu, D. A novel strategy for salts recovery from 1,3-propanediol fermentation broth by bipolar membrane electrodialysis. Sep. Purif. Technol. 2011, 83, 9-14. [CrossRef]

29. Malinowski, J.J. Reactive extraction for downstream separation of 1,3-propanediol. Biotechnol. Prog. 2000, 16, 76-79. [CrossRef]

30. Saxena, R.K.; Anand, P.; Saran, S.; Isar, J. Microbial production of 1,3-propanediol: Recent developments and emerging opportunities. Biotechnol. Adv. 2009, 27, 895-913. [CrossRef]

31. Waszak, M.; Markowska-Szczupak, A.; Gryta, M. Application of nanofiltration for production of 1,3-propanediol in membrane bioreactor. Catal. Today 2016, 268, 164-170. [CrossRef]

32. Müller, A.; Górak, A. Extraction of 1,3-propanediol from aqueous solutions using different ionic liquid-based aqueous two-phase systems. Sep. Purif. Technol. 2012, 97, 130-136. [CrossRef]

33. Laura, M.; Trif, M.; Vodnar, D.C. The effect of crude glycerol impurities on 1,3-propanediol biosynthesis by Klebsiella pneumoniae DSMZ 2026. Renew. Energy 2020, 153, 1418-1427. [CrossRef]

34. Mitrea, L.; Vodnar, D.C. Klebsiella pneumoniae-A useful pathogenic strain for biotechnological purposes: Diols biosynthesis under controlled and uncontrolled pH levels. Pathogens 2019, 8, 293. [CrossRef] [PubMed]

35. Kraus, G.A. Synthetic methods for the preparation of 1,3-propanediol. CLEAN-Soil Air Water 2008, 36, 648-651. [CrossRef]

36. Zeng, A.-P.; Sabra, W. Microbial production of diols as platform chemicals: Recent progresses. Curr. Opin. Biotechnol. 2011, 22, 749-757. [CrossRef] [PubMed]

37. Liu, H.; Xu, Y.; Zheng, Z.; Liu, D. 1,3-Propanediol and its copolymers: Research, development and industrialization. Biotechnol. J. 2010, 5, 1137-1148. [CrossRef] 
38. Wilkens, E.; Ringel, A.K.; Hortig, D.; Willke, T.; Vorlop, K.-D. High-level production of 1,3-propanediol from crude glycerol by Clostridium butyricum AKR102a. Appl. Microbiol. Biotechnol. 2012, 93, 1057-1063. [CrossRef]

39. Lee, C.S.; Aroua, M.K.; Daud, W.M.A.W.; Cognet, P.; Pérès-Lucchese, Y.; Fabre, P.-L.; Reynes, O.; Latapie, L. A review: Conversion of bioglycerol into 1,3-propanediol via biological and chemical method. Renew. Sustain. Energy Rev. 2015, 42, 963-972. [CrossRef]

40. Laura, M.; Călinoiu, L.-F.; Martău, G.-A.; Szabo, K.; Teleky, B.-E.; Mureșan, V.; Rusu, A.; Socol, C.T.; Vodnar, D.C. Poly(vinyl alcohol)-based biofilms plasticized with polyols and colored with pigments extracted from tomato by-products. Polymers 2020, 12, 532. [CrossRef]

41. Szabo, K.; Teleky, B.-E.; Laura, M.; Călinoiu, L.-F.; Martău, G.-A.; Simon, E.; Varvara, R.-A.; Vodnar, D.C. Active packaging-Poly (vinyl alcohol) films enriched with tomato by-products extract. Coatings 2020, 10, 141. [CrossRef]

Publisher's Note: MDPI stays neutral with regard to jurisdictional claims in published maps and institutional affiliations.

(C) 2020 by the authors. Licensee MDPI, Basel, Switzerland. This article is an open access article distributed under the terms and conditions of the Creative Commons Attribution (CC BY) license (http://creativecommons.org/licenses/by/4.0/). 